Technological University Dublin

DÜBLIN

ARROW@TU Dublin

Articles

Centre for Industrial and Engineering Optics

2012-1

\title{
New Non-Toxic Holographic Photopolymer Material
}

Dervil Cody

Technological University Dublin, dervil.cody@tudublin.ie

Izabela Naydenova

Technological University of Dublin, izabela.naydenova@tudublin.ie

Emilia Mihaylova

Technological University of Dublin, emilia.mihaylova@tudublin.ie

Follow this and additional works at: https://arrow.tudublin.ie/cieoart

Part of the Optics Commons

\section{Recommended Citation}

Cody, D., Naydenova, I., Mihaylova, E. (2012) New non-toxic holographic photopolymer. Journal of Optics, Vol. 14, no.1. doi:10.1088/2040-8978/14/1/015601

This Article is brought to you for free and open access by the Centre for Industrial and Engineering Optics at ARROW@TU Dublin. It has been accepted for inclusion in Articles by an authorized administrator of ARROW@TU Dublin. For more information, please contact arrow.admin@tudublin.ie, aisling.coyne@tudublin.ie, gerard.connolly@tudublin.ie.

Funder: Irish Research Council for Science, Engineering and Technology

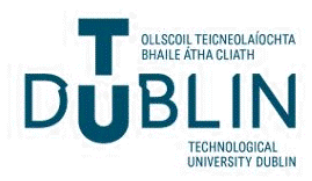




\title{
New non-toxic holographic photopolymer material
}

\author{
D Cody $^{1,2}$, I Naydenova ${ }^{1,2}$ and E Mihaylova ${ }^{1,2,3, *}$ \\ ${ }^{1}$ Centre for Industrial and Engineering Optics, Dublin Institute of Technology, Dublin 8, Ireland \\ ${ }^{2}$ School of Physics, College of Sciences and Health, Dublin Institute of Technology, Dublin 8, \\ Ireland \\ ${ }^{3}$ Department of Mathematics and Physics, Agricultural University, Plovdiv, Bulgaria \\ *corresponding author e-mail: emilia.mihaylova@dit.ie
}

\begin{abstract}
There is an increasing need for environmentally friendly holographic recording materials which can be produced in bulk with little risk to the health of workers in manufacturing. This is why the development of non-toxic photopolymer materials is crucial, and has attracted attention in recent years. Composition and preliminary characterization of a new non-toxic photopolymer material are presented. It operates well at a range of spatial frequencies, and achieves diffraction efficiencies and refractive index modulation comparable to the known acrylamide-based photopolymers.
\end{abstract}

\section{Introduction}

Acrylamide-based photopolymers are fast becoming one of the most popular recording media for different holographic applications. Their high sensitivity, wide dynamic range and self processing nature, together with their low cost of production, make them an excellent candidate for applications such as holographic sensors, diffractive optics and data storage. However acrylamide (AA) is a toxic chemical [1-3] and has been classified by the World Health Organization as probably carcinogenic to humans, following studies conducted by the International Agency for Research on Cancer [4].

In this paper, the design and testing of a new non-toxic and environmentally-compatible photopolymer material is described. The improved photopolymer is shown to have holographic recording features similar to those of the standard AA-based photopolymer [5]. It has already been shown to surpass the holographic recording capabilities of other reported low toxicity photopolymer alternatives [6-8].

Any new non-toxic monomer must be compatible with the other components of the photopolymer composition. It must be hydrophilic, and it must react through a radical chain mechanism. A detailed description of the radical chain steps and reaction equations is given elsewhere [9].

In the work presented here, AA is replaced by Diacetone Acrylamide (DA) as the main monomer in the photopolymer composition. DA is a crystalline solid and contains only $0.1 \mathrm{wt} \% \mathrm{AA}$, and is not a probable carcinogen, according to research reported by the IARC [10]. It is classified as a category 4 material in terms of acute toxicity, compared to AA which is a high risk category 3 material [11,12]. Aside from its low toxicity, DA is highly hydrophilic, and it readily polymerizes via a radical chain mechanism with a variety of co-monomers [13].

\section{Experimental}

\subsection{Layer Preparation}


The DA photopolymer layers were prepared by mixing 1.0g DA, $0.2 \mathrm{~g} \mathrm{~N}, \mathrm{~N}$-methylene-bisacrylamide (BA), $2 \mathrm{ml}$ triethanolamine (TEA) and $4 \mathrm{ml}$ Erythrosin B $0.11 \% \mathrm{wt} / \mathrm{vol}$ dye solution (EB) to $20 \mathrm{ml}$ of $10 \% \mathrm{wt} / \mathrm{vol}$ polyvinyl alcohol (PVA). The photopolymer solution was then deposited on to glass slides (76 x 26mm) and allowed to dry for 12-24 hours in darkness under normal laboratory conditions $\left(20-25^{\circ} \mathrm{C}, 40-60 \% \mathrm{RH}\right)$. Layer thickness was measured using a white-light surface profiler (Micro XAM S/N 8038). The preparation of the acrylamide containing layers, is described elsewhere [10] for comparison purposes.

\subsection{Experimental Set-up}

A two-beam holographic optical setup (figure 1) with an angle of $30^{\circ}$ between the beams was used to record unslanted transmission gratings using a $532 \mathrm{~nm} \mathrm{Nd}: \mathrm{YVO}_{4}$ laser. Gratings were recorded in the layers with an exposure of $200 \mathrm{~mJ} / \mathrm{cm}^{2}$ at a spatial frequency of 1000 lines $/ \mathrm{mm}$. The recording intensity was controlled by a variable neutral density filter. The absorption of the photopolymer at $633 \mathrm{~nm}$ is negligible, so a $633 \mathrm{~nm}$ He-Ne laser was used as a probe beam at the Bragg angle to enable the diffracted beam intensity to be monitored in real time. The angular selectivity of the gratings was measured after holographic recording was finished. In order to measure the diffracted intensity dependence on the incident angle of the probe beam, the grating was placed on a rotational stage (Newport, ESP 300). An optical power meter (Newport 1830-C) recorded the intensity of the diffracted beam and the data was transferred to a computer.

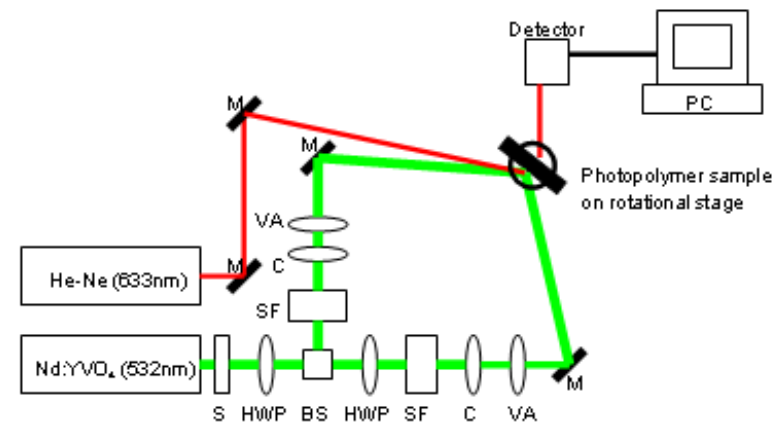

Figure 1. Experimental setup: S: shutter, HWP: half wave plate, BS: beam splitter, SF: spatial filter, C: collimator, VA: variable aperture, M: mirror.

\section{Composition Optimization}

\subsection{DA monomer optimization}

First, the concentration of the DA monomer in the photopolymer composition was optimized. Concentrations of DA monomer varying from $25-75 \mathrm{mg} / \mathrm{ml}$ were tested, without addition of cross-linking monomer BA. Transmission gratings were then recorded using with these layers. The diffraction efficiency of the gratings recorded in the layers was calculated using the formula

$$
\eta=\frac{I_{d}}{I_{\text {in }}} \times 100
$$

where Id $=$ diffracted beam intensity, Iin $=$ incident intensity and $\_=$diffraction efficiency.

As can be seen from figure 2, there is steep increase in the diffraction efficiency with increasing concentration of DA. However above $\sim 60 \mathrm{mg} / \mathrm{ml}$, the quality of the layers begins to deteriorate as saturation of the amount of monomer that can be dispersed in the binder has been reached, and the diffraction efficiency falls off due to the poor optical quality of the layers. 


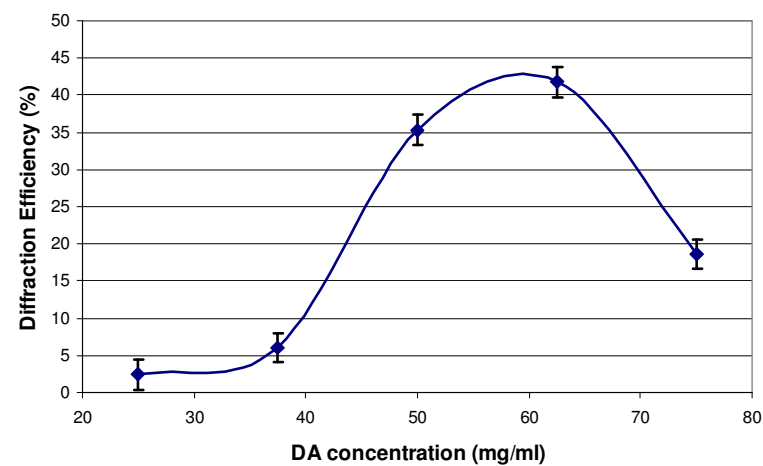

Figure 2. Graph of diffraction efficiency vs. diacetone acrylamide concentration.

\subsection{Cross-linker optimization}

Cross-linking monomer BA (N, N'-Methylenebisacrylamide) was then added to the photopolymer solution. The function of the cross-linker is to hold the polymer chains together in the grating once it is formed, preventing polymer diffusion. The presence of the cross linker prohibits post-recording decay of diffraction gratings. This is shown in figure 3. The total amount of monomer was kept constant at $1.25 \mathrm{~g}(=62.5 \mathrm{mg} / \mathrm{ml})$ and the ratio of the DA: BA was varied. The different compositions tested are shown in Table 1. Photopolymer layers prepared with composition B were the most stable. The other solutions produced layers from which BA precipitated out of the layers, as the saturation point of the solution had been reached. This effect was not initially observed in layers of composition B, but occurred 24 hours after holographic recording. To prevent this and improve the material's shelflife, the amount of BA was reduced by $0.05 \mathrm{~g}$ ( $20 \%$ of the initial value) without a significant decrease in diffraction efficiency. The final composition is shown in Table 1.

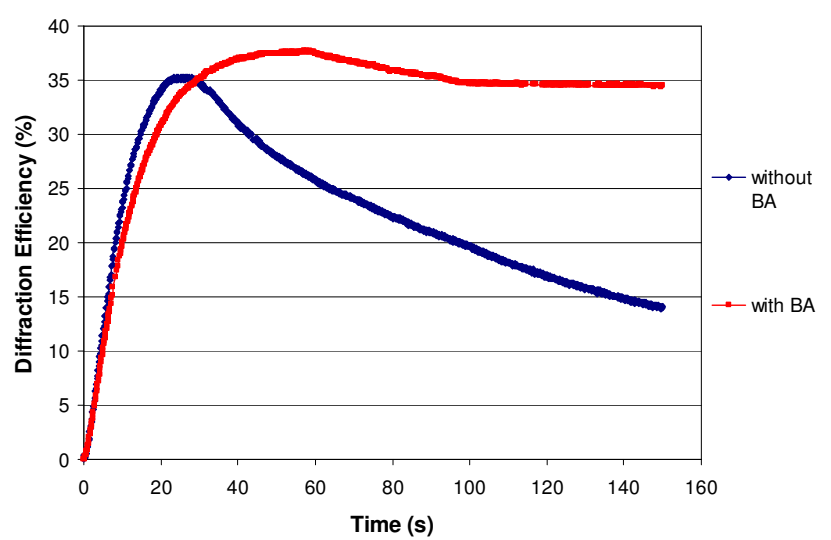

Figure 3. Graph of real-time diffraction efficiency growth curves for DA photopolymers without and with bisacrylamide (final composition in Table 1). 
Table 1. Compositions for BA Concentration Optimization

\begin{tabular}{llllll}
\hline Composition & $\begin{array}{l}\text { PVA } \\
(\mathrm{ml})\end{array}$ & $\begin{array}{l}\text { TEA } \\
(\mathrm{ml})\end{array}$ & $\begin{array}{l}\text { EB } \\
\text { dye } \\
(\mathrm{ml})\end{array}$ & $\begin{array}{l}\text { DA } \\
(\mathrm{g})\end{array}$ & $\begin{array}{l}\text { BA } \\
(\mathrm{g})\end{array}$ \\
\hline $\mathrm{A}$ & 20 & 2 & 4 & 1.125 & 0.12 \\
& & & & & 5 \\
$\mathrm{~B}$ & 20 & 2 & 4 & 1.0 & 0.25 \\
$\mathrm{C}$ & 20 & 2 & 4 & 0.875 & 0.37 \\
& & & & & 5 \\
$\mathrm{D}$ & 20 & 2 & 4 & 0.75 & 0.5 \\
$\mathrm{E}$ & 20 & 2 & 4 & 0.625 & 0.62 \\
& & & & & 5 \\
F & 20 & 2 & 4 & 0.5 & 0.5 \\
Final & 20 & 2 & 4 & 1.0 & 0.2 \\
\hline
\end{tabular}

\section{Results and Discussion}

4.1 Spatial Frequency Dependence of new Photopolymer

Once the composition had been optimized for the new monomer, the spatial frequency dependence of the non-toxic photopolymer was investigated. Transmission gratings were recorded in 55-65 $\mu \mathrm{m}$ thick layers at spatial frequencies of 1000 and $3000 \mathrm{l} / \mathrm{mm}$.

4.1.1 Photopolymer response at $1000 \mathrm{l} / \mathrm{mm}$. The recording intensity was varied in the range $1-5 \mathrm{~mW} / \mathrm{cm}^{2}$. As shown in figure 4 , for $1000 \mathrm{l} / \mathrm{mm}$ the DA composition reaches a maximum refractive index modulation of $\sim 3.33 \times 10^{-3}$ after being exposed to an intensity of $2 \mathrm{~mW} / \mathrm{cm}^{2}$ for 55 seconds. The refractive index modulation in the acrylamide based photopolymer composition can reach $\sim 5 \times 10^{-3}$ after 50 seconds of exposure to $4 \mathrm{~mW} / \mathrm{cm}^{2}$.

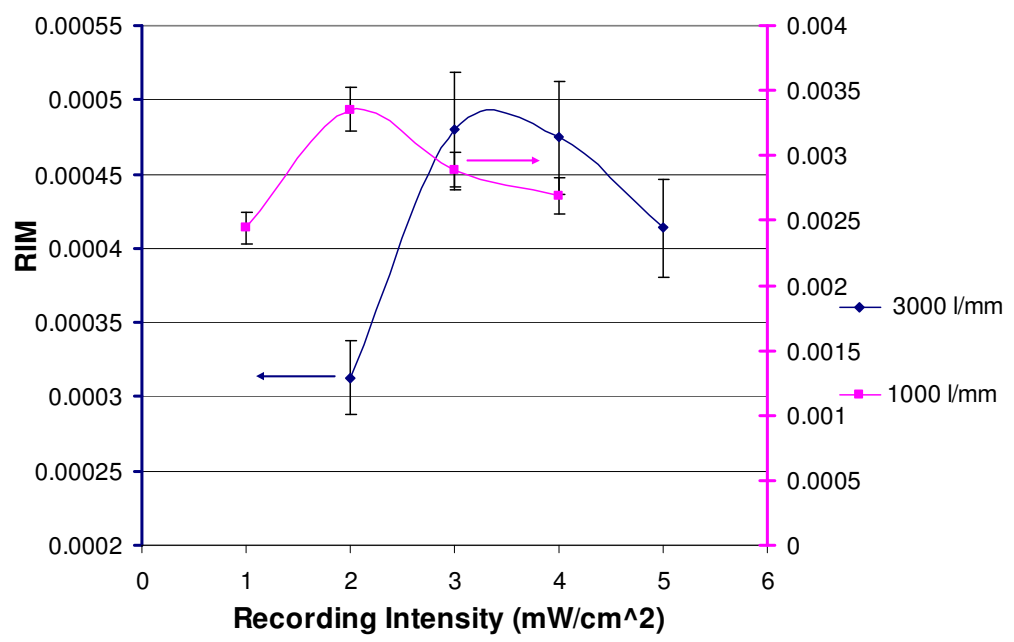

Figure 4. Refractive index modulation vs. recording intensity for 1000 (right hand vertical axis) and 3000 1/mm (left hand vertical axis). 
4.1.2 Photopolymer response at $3000 \mathrm{l} / \mathrm{mm}$. At $3000 \mathrm{l} / \mathrm{mm}$ the maximum achievable refractive index modulation for DA is $4.7 \times 10^{-4}$ with an exposure of $3 \mathrm{~mW} / \mathrm{cm}^{2}$ for 32 seconds. The acrylamide photopolymer can reach a refractive index modulation of $8.5 \times 10^{-4}$ after a relatively low exposure time of 8 seconds at $7 \mathrm{~mW} / \mathrm{cm}^{2}$. The Centre for Industrial and Engineering Optics (IEO) at Dublin Institute of Technology has developed a two-way diffusion model which explains this experimentally observed decrease in refractive index modulation at higher spatial frequencies [14]. Optimisation of the diacetone acrylamide photopolymer will need to be done to further improve its suitability for high spatial frequency recording. One option is to decrease the permeability of the photopolymer matrix, which would prevent the diffusion of short polymer chains [15]. The addition of different types of nanoparticles to the composition will be investigated, as this has previously been shown to improve the sensitivity and refractive index modulation of photopolymer materials [16]. Characterization of the photopolymer for recording in reflection mode is in progress.

\section{Conclusion}

The development of a new non-toxic holographic photopolymer material has been discussed. The photopolymer composition has been optimized for the non-toxic monomer, and its spatial frequency dependence on the Refractive Index Modulation in transmission mode of recording has been investigated. The new material has been observed to reach refractive index modulation up to $3.3 \times 10^{-3}$, and can reach diffraction efficiencies $>90 \%$ in $70 \mu \mathrm{m}$ thick layers. It is suitable as an environmentally friendly alternative to the known acrylamide photopolymers [17-21] for holographic applications. Further characterization of the materials holographic recording capabilities is currently being carried out. Optimization is also underway to improve this material's high spatial frequency response.

\section{Acknowledgements}

The authors acknowledge the Irish Research Council for Science, Engineering and Technology (IRCSET) for financial support.

\section{References}

[1] McCollister D D, Oyen F and Rowe V K 1964 Toxicology of acrylamide Tox. App. Pharm.6 172-81

[2] Shipp A, Lawrence G, Gentry R, McDonald T, Bartow H, Bounds J, Macdonald N, Clewell H, Allen B and Van Landingham C 2006 Acrylamide: review of toxicity data and dose-response analyses for cancer and noncancer effects Crit. Rev. Tox. 36 481-608

[3] King D J and Noss R R 1989 Toxicity of polyacrylamide and acrylamide monomer Rev. Environ. Health 8 3-16

[4] Health implications of acrylamide in food: report of a joint FAO/WHO consultation, WHO Headquarters, Geneva, Switzerland, 25-27 June, 2002

[5] Martin S, Leclere P, Renotte Y, Toal V and Lion Y 1994 Characterization of an acrylamide-based dry photopolymer holographic recording material Opt. Eng. 33 3942-6

[6] Ortuno M, Fernandez E, Gallego S, Belendez A and Pascual I 2007 New photopolymer holographic recording material with sustainable design Opt. Express 15 12426-35

[7] Gallego S, Marquez A, Ortuno M, Marini S and Frances J 2011 High environmental compatibility photopolymers compared to PVA/AA based materials at zero spatial frequency limit Opt. Mater 33 531-7

[8] Olivares-Perez A, Hernandez-Garay M P, Fuentes-Tapia I and Ibarra-Torres J C 2011 Holograms in polyvinyl alcohol photosensitized with $\mathrm{CuCl} 2(2 \mathrm{H} 2 \mathrm{O})$ Opt. Eng. 50 065801-6

[9] Mahmud M S, Naydenova I, Babeva T, Jallapuram R, Martin S and Toal V 2010 Determination of threshold exposure and intensity for recording holograms in thick green-sensitive acrylamide-based photopolymer Appl. Opt. $495276-83$

[10] Siemiatycki J, Richardson L, Straif K, Latreille B, Lakhani R, Campbell S, Rousseau M and Boffetta P 2004 Listing occupational carcinogens Environ. Health Perspect. 112 1447-59

[11] Acrylamide; Sigma-Aldrich; http://www.sigmaaldrich.com/catalog/DisplayMSDSContent.do (accessed $30 / 6 / 11)$ 
[12] Diacetone Acrylamide; Sigma-Aldrich; http://www.sigmaaldrich.com/catalog/DisplayMSDSContent.do (accessed 30/6/11)

[13] Coleman L E, Bork J F, Wyman D P and Hoke D I 1965 Synthesis and polymerization of N[2-(2-methyl-4oxopentyl)]-acrylamide-A new reactive vinyl monomer J. Polym. Sci. 3 1601-8

[14] Naydenova I, Jallapuram R, Howard R, Martin S and Toal V 2004 Investigation of the diffusion processes in a

[15] Babeva T, Naydenova I, Mackey D, Martin S and Toal V 2010 Two-way diffusion model for short-exposure holographic grating formation in acrylamide-based photopolymer Opt. Soc. Amer. 27 197-203

[16] Naydenova I, Leite E, Babeva Tz, Pandey N, Baron T, Yovcheva T, Sainov S, Martin S, Mintova S and Toal V 2011 Optical properties of photopolymerizable nanocomposites containing nanosized molecular sieves $J$. Opt. 13, 044019

[17] Martin S, Feely C A and Toal V 1997 Holographic characteristics of an acrylamide based recording material Opt. Soc. Amer. 36 5757-68

[18] Gallego S, Ortuno M, Neipp C, Garcia C, Belendez A and Pascual I 2003 Overmodulation effects in volume holograms recorded on photopolymers Opt. Comm. 215 263-9

[19] Blaya S, Carretero L, Mallavia R, Fimia A, Madrigal R F, Ulibarrena M and Levy D 1998 Optimization of an acrylamide-based dry film used for holographic recording Opt. Soc. Amer. 37 7604-10

[20] Huawen Y, Mingju H, Zhongyu C, Lisong H and Fuxi G 2001 Optimization of two-monomer-based photopolymer used for holographic recording Mater. Lett. 56 3-8

[21] Hai L, Ruo-Ping L, Cai-Xia S, Yong X, Dao-Guang T and Ming-ju H 2010 Holographic property of photopolymers with different amine photoinitiators Chin. Phys. B 19 242121-7 